\title{
ETV Gene Rearrangement Negative
}

National Cancer Institute

\section{Source}

National Cancer Institute. ETV Gene Rearrangement Negative. NCI Thesaurus. Code C160360.

A genetic finding indicating that rearrangement of ETV family genes have not been detected in a sample. 